\title{
Meiotic Behaviour of Spontaneous and Mutagen Induced Partial Desynaptic Plants in Pearl Millet
}

\author{
R. B. Singh, B. D. Singh, Vijay Laxmi and R. M. Singh \\ Department of Genetics and Plant Breeding, Banaras Hindu University, \\ Varanasi, India
}

Received June 10, 1975

Desynapsis is known in a number of plants, such as barley (Enns and Larter 1960), sorghum (Ross et al. 1960, Magoon et al. 1961), oats (Dyck and Rajhathy 1965, Singh and Wallace 1966) and bajra (Krishnaswamy et al. 1949, Patil and Vohra 1962, minocha et al. 1968). In desynaptic plants, the pachytene pairing is normal, but at Metaphase I (MI) a variable number of univalents are present. At anaphase I (AI), unequal separation of chromosomes, chromatin bridges and lagging chromosomes have been observed (Minocha et al. 1968). The cytogenetics of desynaptic plants has been studied in some detail, but the basic mechanisms underlying it are not yet known. Celarier (1955) has suggested that reduction in the number of chiasmata may be an important factor causing desynapsis, but it is not certain if it is the cause or the result of desynapsis (Minocha et al. 1968).

The present study was undertaken to study the meiotic behaviour of spontaneous and mutagen induced partial desyptic plants in pearl millet (Pennisetum typhoides $\mathbf{S}$. and $\mathbf{H}$.).

\section{Materials and methods}

The PMC's of sporadically occurring semisterile plants of a normal population of inbred T55 were examined. One plant was partially desynaptic. Its meiotic behaviour was studied in some detail.

Dry seeds of inbreds Tif $23 \mathrm{~A}, 23 \mathrm{D}_{2} \mathrm{~A}$ (male steriles); Tif 23B, $23 \mathrm{D}_{2} \mathrm{~B}$ (maintainers); K560, Bil3B and J104 (restorers), and hybrids HB1 (Tif 23A $\times$ Bi13B), HB3 (Tif $23 \mathrm{~A} \times \mathrm{J} 104)$ and HB5 (Tif $23 \mathrm{~A} \times \mathrm{K} 559$ ), were treated with 10,20 and $30 \mathrm{kr}$ gamma-rays or with $0.2,0.4$ and $0.6 \%$ EMS (Ethyl methanesulphonate), or with a combination of the two. The material was grown in field during normal growing season (Singh et al. communicated).

PMCs were fixed in modified Carnoy solution ( 1 acetic acid: 3 chloroform: 6 ethyl alcohol) and stored in $70 \%$ ethyl alcohol. Squashes were made in $2 \%$ acetocarmine.

\section{Results and discussion}

The spontaneous partially desynaptic plant was recovered from a normal population of inbred T55. In the mutagen treated material, 15 plants were partially desynaptic: 14 plants were recovered from the male sterile line Tif $23 \mathrm{~A}$ its maintainer Tif 23B, and one from the restorer K560. Out of these 15 plants, nine were recovered 
from gamma-irradiated populations, three from those treated with EMS and the other three from those receiving combination treatments. Desynapsis occurs spontaneously in many plant species (Enns and Larter 1960, Ross et al. 1960, Magoon et al. 1961, Krishnaswamy et al. 1949, Patil and Vohra 1962, Minocha et al. 1967), and is also induced by gamma-rays and EMS (Gottschalk and Bauquar 1971, Tyagi 1973, Srivastava 1974, Sharma and Reinbergs 1974). It is evident that the different genotypes studied differed markedly with respect to induction of partial desypsis in response to mutagen treatments. The genetic constitution of the organism affects considerably its response to mutagen treatments with respect to induced mutations (Goud 1967, Goud et al. 1970) and cytological aberrations (Laxmi et al. 1975). Furthermore, gamma-rays were more effective than EMS or combination treatments in induction of desynapsis. Gamma-rays are known to be more effective than EMS (Sjodin 1971, Siddiq 1973) and combination treatments (Laxmi et al. 1975) in inducing cytological aberrations.

\section{Metaphase I}

In the normal inbreds of pearl millet, seven bivalents were regularly seen at diakinesis and metaphase I (MI). This does not agree with the findings of Pontulu and Manga (1972) who observed a number of anomalies in pearl millet inbreds. In the case of desynaptic plants, both spontaneous and induced, the pachytene pairing was complete and normal (Fig. 1). At diakinesis and metaphase I, 2-14 univalents were observed (Figs. 2-6). The frequency of cells with univalents as well as the number of univalents per cell was higher at MI compared to those at diakinesis. However, an appreciable proportion of cells had 7II at MI (Table 1). Earlier

Table 1. Chromosome associations in the spontaneous and mutagen induced desynaptic plants of pearl millet

\begin{tabular}{|c|c|c|c|c|c|c|c|c|c|}
\hline \multirow{2}{*}{ Stage } & \multirow{2}{*}{$\begin{array}{l}\text { Number } \\
\text { of cells } \\
\text { observed }\end{array}$} & \multicolumn{8}{|c|}{ Frequency } \\
\hline & & $7_{\mathrm{II}}$ & $6_{I I}+2 \mathrm{I}$ & $5_{I I}+4 I$ & $4_{I I}+6 r$ & $3_{I I}+8_{I}$ & $2 \mathrm{II}+10_{\mathrm{I}}$ & $1_{I I}+12_{I}$ & $14_{I}$ \\
\hline \multicolumn{10}{|c|}{ Spontaneous } \\
\hline$D^{*}$ & 248 & 52.4 & 21.4 & 17.7 & 6.9 & 1.6 & 0.0 & 0.0 & 0.0 \\
\hline $\mathbf{M}$ & 394 & 44.7 & 24.1 & 10.9 & 10.7 & 5.8 & 2.8 & 1.0 & 0.0 \\
\hline \multicolumn{10}{|c|}{ Mutagen induced $* *$} \\
\hline $\mathrm{D}$ & 292 & 35.0 & 24.3 & 14.5 & 12.6 & 8.5 & 5.3 & 0.0 & 0.0 \\
\hline $\mathbf{M}$ & 318 & 26.0 & 23.8 & 18.5 & 13.2 & 9.4 & 5.3 & 1.8 & 1.2 \\
\hline
\end{tabular}

workers have also observed a variable number of univalents per cell (Krishnaswami et al. 1949, Patil and Vohra 1967, Minocha et al. 1967), and a much higher proportion (15.8\%) of cells with 14I (Minocha et al. 1967). Furthermore, Minocha et al. (1967) observed a higher frequency of cells with 7II and a lower one with 14I at MI compared to those at diakinesis. The findings of the present study do not agree with the above observations; these differences could have been due to the differences in the genotypes of the inbreds from which the partial desynaptic individuals were isolated. 


\section{Distribution of univales at $M I$}

The distribution of univalents at MI in desynaptic plants may be either polar or more or less equatorial (Östergren and Vigfösson 1953, John and Lewis 1965) and may be influenced by the number of bivalents per cell, i.e., when the number of

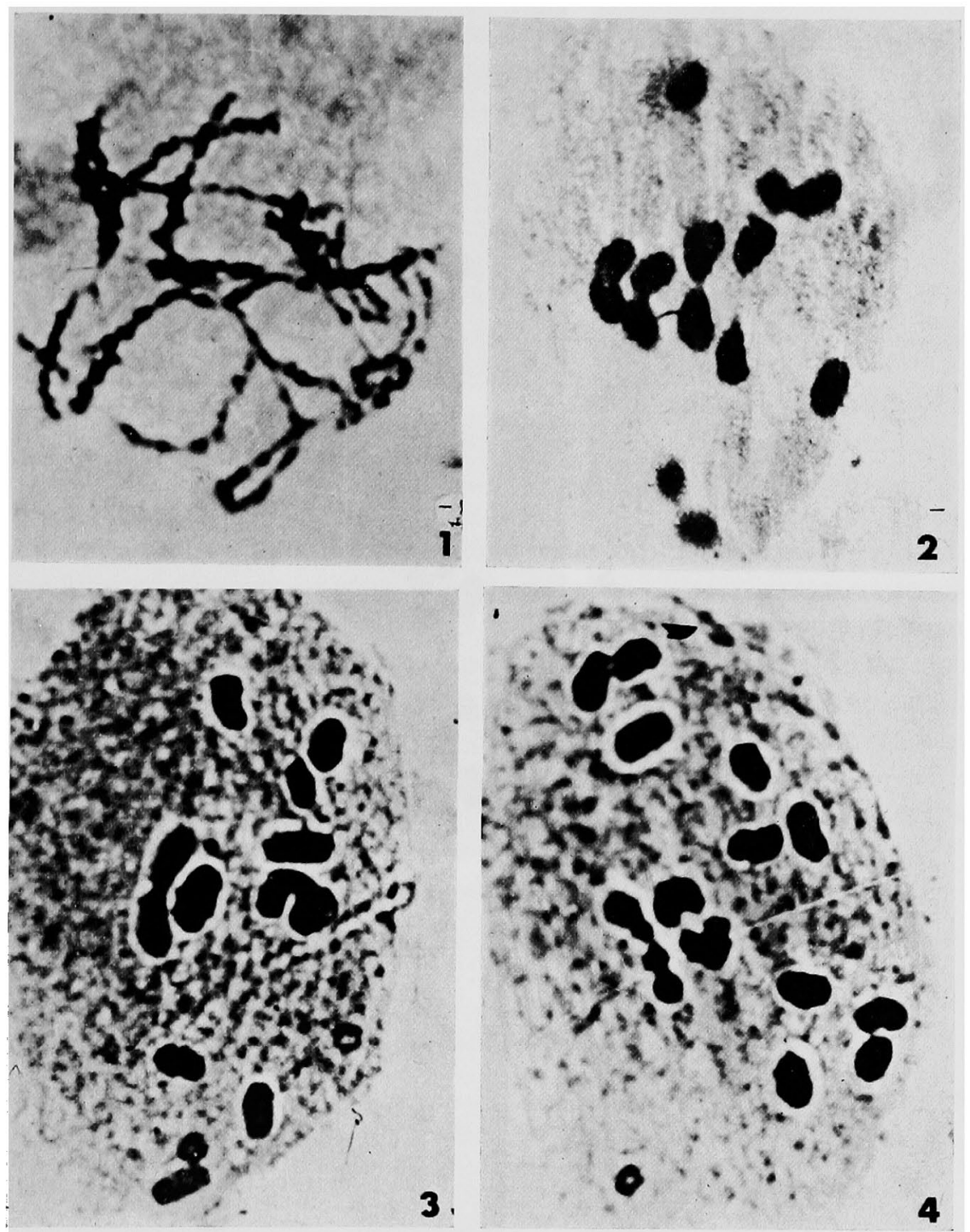

Figs. 1-4. Meiosis in partially desynaptic pearl millet. 1, pachytene showing normal pairing. $2-4, \mathrm{MI}$ in mutagen induced desynaptic plants with 6,8 and 10 univalents.

bivalents is small, the univalents tend to be polar, but when many bivalents occur, the univalents tend to be at the equatorial plate (Östergren and Vigfösson 1953). In the present study, the univalents were randomly distributed and did not appear to be affected by the number of bivalents per cell (Figs. 2-6). In some cases even the bivalents were not arranged on the equatorial plate (Figs. 5, 6). However, often 
many of the univalents were present in pairs (Fig. 6), which is apparently due to the prophase pairing of the homologues.

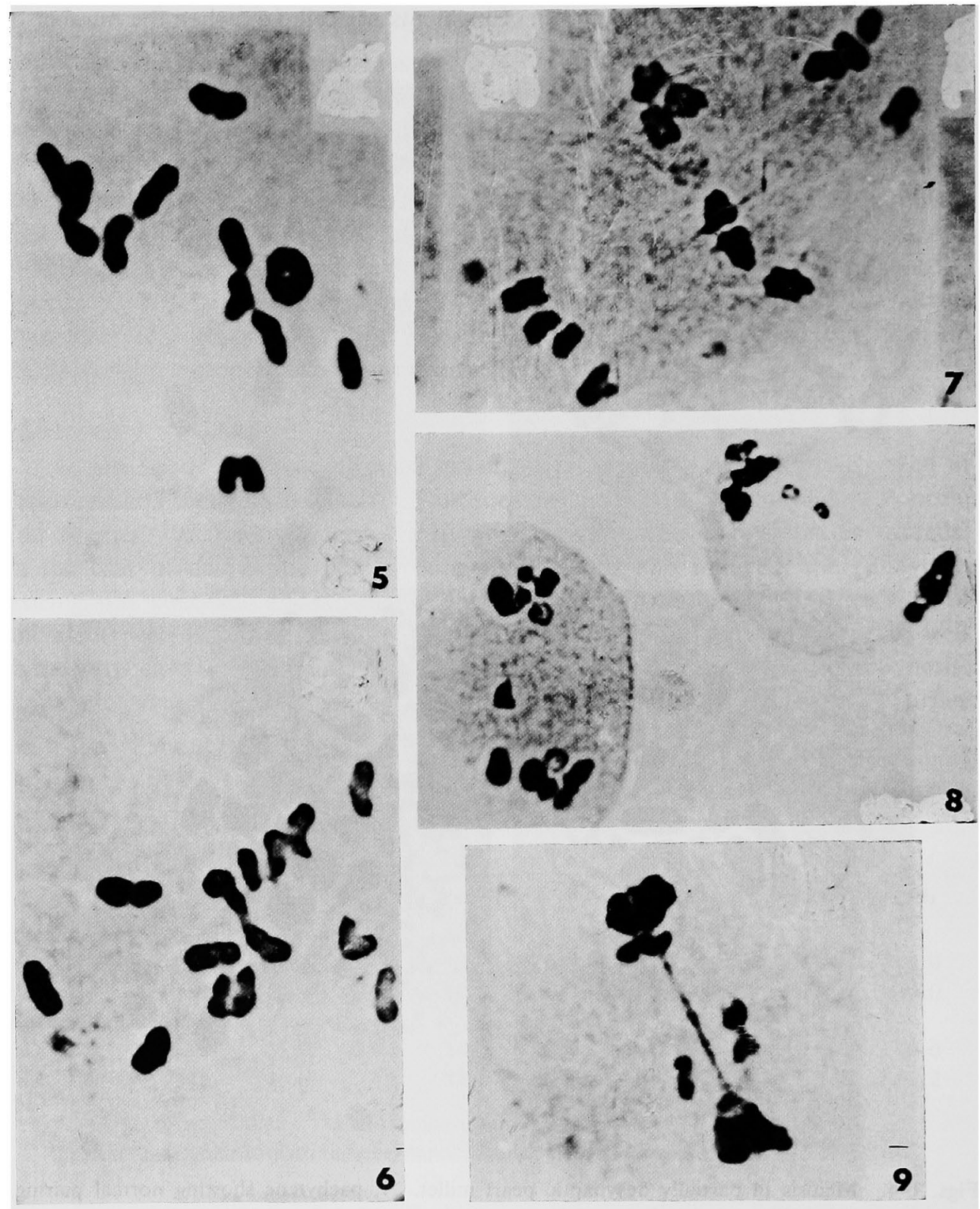

Figs. 5-9. Meiosis in partially desynaptic pearl millet. 5 and 6, MI in the spontaneous desynaptic plants with 4 and 10 univalents, respectively. 7 and 8, laggards at $\mathrm{AI}$ in the spontaneous desynaptic plant. 9 , bridge and laggards at $\mathrm{AI}$ in the spontaneous desynaptic plant.

\section{Anaphase I}

The chromosome distribution was normal in the majority of the cells. Unequal chromosome distributions, viz., 8:6 and 9:5, were also observed. Such unequal 
distributions of chromosomes at AI would lead to formation of aneuploid gametes, which in turn would produce aneuploid plants. The spontaneous desynaptic strain has been used for isolation of trisomic lines. In the case of the spontaneous desynaptic plant, an appreciable proportion $(31.5 \%)$ of cells showed 1 to 6 lagging chromosomes (Figs. 7,8$)$; the majority $(12.5 \%$ ) showing 3 laggards per cell (Table 2). In addition, chromatin bridges were observed in $14.8 \%$ of cells at telophase I (Fig. 9) of this plant. Desynaptic plants have been shown to exhibit a number of anaphase irregularities (Krishnaswamy et al. 1949, Patil and Vohra 1962, Minocha et al. 1967).

Table 2. Chromosome distribution at anaphase $I$ in spontaneous and mutagen induced partial desynaptic plants of pearl millet

\begin{tabular}{|c|c|c|c|c|c|c|c|c|c|c|}
\hline \multirow{2}{*}{ Material } & \multirow{2}{*}{$\begin{array}{l}\text { Number } \\
\text { of cells } \\
\text { studied }\end{array}$} & \multicolumn{3}{|c|}{ Distribution } & \multicolumn{6}{|c|}{ Cells with Laggards } \\
\hline & & $7: 7$ & $8: 6$ & $9: 5$ & 1 & 2 & 3 & 4 & 5 & 6 \\
\hline Spontaneous & 184 & 65.8 & 2.7 & - & 1.6 & 5.9 & 12.5 & 8.2 & 2.2 & 1.1 \\
\hline $\begin{array}{l}\text { Mutagen } \\
\text { induced }\end{array}$ & 191 & 78.7 & 18.2 & 3.1 & - & - & - & - & - & - \\
\hline
\end{tabular}

It is important to note that the meiotic behaviour of the spontaneous and the mutagen induced desynaptic plants differed markedly. The spontaneous desynaptic plant had a higher frequency of bivalents per cell than those induced with the mutagens; the frequency of cells with 7II was much higher in the former. In the mutagen induced desynaptic plants, cells with 14I were also observed, while in the spontaneous one at least one bivalent per cell was observed. Furthermore, the spontaneous desynaptic plant showed laggards and chromatin bridges in an appreciable frequency of cells, while the mutagen induced desynaptic plants did not show these irregularities. These differences may have been due to gene mutations induced by the mutagens or due to the differences in the genotype of the inbreds from which they were isolated.

Table 3. Chiasma frequency in normal and spontaneous and mutagen induced partial desynaptic plants in pearl millet

\begin{tabular}{clcc}
\hline \multirow{2}{*}{ Material } & Stage & \multicolumn{2}{c}{ Number of chiasmata } \\
\cline { 3 - 4 } & & per cell & per bivalent \\
\hline Spontaneous & & 16.6 & 2.3 \\
Control & Diplotene & 14.3 & 2.0 \\
& Diakinesis & 10.9 & 1.6 \\
Desynaptic & Diplotene & 8.7 & 1.2 \\
& Diakinesis & 12.1 & 1.7 \\
Mutagen induced* & & 11.3 & 1.6 \\
Control & Diakinesis & 8.5 & 1.2 \\
Desynaptic & Metaphase I & 5.8 & 0.8 \\
& Diakinesis & Metaphase I &
\end{tabular}

* Average of the three inbreds (control) and the 15 desynaptic plants, respectively. 


\section{Chiasma frequency}

The frequency of chiasmata was appreciably lower in the case of desynaptic plants as compared to the normal ones (Table 3). This is in agreement with the observations of Minocha et al. (1968). It has been suggested that the lower ferquency of chiasmata in the desynaptic plants compared to the normal ones may be one of the important factors causing desynapsis (Celarier 1955). However, it is not clear whether the reduced chiasma frequency is the cause or the result of desynapsis (Minocha et al. 1968, Sharma and Reinbergs 1974), since desynapsis would occur only when at least some of the homologous chromosomes occur as univalents during diakinesis and/or MI, which would mean a lower chiasma frequency.

\section{Sumary}

Partial desynaptic plants were isolated from normal population of pearl millet (Pennisetum typhoides S. and H.) inbred T55 and mutagen (EMS and gamma-rays) treated populations of inbreds Tif 23A, Tif 23B and K560. The pachytene pairing was complete and normal. A variable number (2-14) of univalents occurred at MI. Anaphase I separation was normal in the majority $(66-79 \%)$ of the cells; many showed 8:6 and 9:5 chromosome separation. The spontaneous desynaptic plant showed laggards and chromatin bridges at anatelophase I, while the induced ones did not show these aberrations. Chiasma frequency in the desynaptic plants was lower than that in the normal controls.

\section{References}

Dyck, P. L. and Rajhathy, T. 1965. A desynaptic mutant in Avena strigosa. Can. J. Genet. Cytol. 7: 418-421.

Enns, H. and Larter, E. N. 1960 . Note on the inheritance of $d s$ : a gene governing meiotic chromosome behaviour in barley. Can. J. Pl. Sci. 40: 570-571.

Gottschalk, W. and Bauquar, S. R. 1971. Desynapsis in Pisum sativum induced by gene mutation. Can. J. Genet. Cytol. 13: 138-143.

Goud, J. V. 1967. Induced mutations in bread wheat. Indian J. Genet. 27: 40-50.

-, Nayar, M. D. and Rao, M. G. 1970. Mutagenesis in Sorghum. Indian J. Genet. 30: 81-89.

John, B. and Lewis, K. R. 1965. The Meiotic System. Protoplasmatologia Bd. VI, Fr. Springer Verlag, Wein, New York.

Krishnaswamy, N., Raman, V. S. and Madhavamenon, P. 1949. Abnormal meiosis in Pennisetum typhoides I. Desynapsis. Proc. Indian Nat. Acad. Sci. 30:B 195-206.

Laxmi, V., Singh, R. B., Singh, B. D. and Singh, R. M. 1975. Induction of translocations and trisomics in pearl millet by gamma-ray and EMS treatments. Indian J. Expl. Biol. 13: 460-464.

Magoon, M. L., Ramanna, M. S. and Shambulingappa, K. G. 1961. Desynapsis and spontaneous chromosome breakage in Sorghum purpureosericeum. Indian J. Genet. 21: 87-97.

Minocha, J. L., Gill, B. S. and Singh, S. 1968. Desynapsis in pearl millet. J. Res. Punjab Agric. Univ. 5 (Suppl.): 32-36.

Östergren, G. and Vigfösson, E. 1953. On position correlation of univalents and quasi bivalents formed by sticky univalents. Hereditas 39: 33-50.

Patil, B. D. and Vohra, S. K. 1962. Desynapsis in Pennisetum typhoides. Curr. Sci. 31: 345-346. Pantulu, J. V. and Manga, V. 1972. Cytology of inbreds and $F_{1}$ hybrids of pearl millet. Theor. Appl. Genet. 42: 69-74. 
Ross, J. V., Sanders, M. E. and Franzke, C. J. 1960. Asynapsis in Sorghum. Hereditas 46: 570-580.

Sharma, R. K. and Reinberg, E. 1974. Cytogenetic analysis of a desynaptic mutant in barley (Hordeum vulgare L.). Cytologia 39: 77-81.

Siddiq, E. A. 1973. Cytogenetical effects of physical and chemical mutagens in rice. Indian J. Genet. 33: 162-171.

Singh, R. M. and Wallace, A. T. 1967. Monosomics of Avena byzantina C. Koch. I. Karyotype and chromosome pairing studies. Can. J. Genet. Cytol. 9: 87-96.

Singh, R. B., Laxmi, V., Singh, B. D. and Singh, R. M. Induction of resistance to disease in pearl millet inbreds by gamma-rays and EMS treatments. Indian J. Genet. (Communicated).

Sjodin, J. 1971. Induced translocations in Vicia faba L. Hereditas 68: 1-34.

Srivastava, H. M. 1974. Radiation induced desynaptic mutants in barley. Cytologia 39: 63-68.

Tyagi, B. R. 1972. Studies on chromosomal interchanges in pearl millet (Pennisetum typhoides) Stapf. and Hubb. Ph.D. Thesis, Meerut University, Meerut. 